\title{
TRADUZINDO O DIALETO DO PERSONAGEM CHICO BENTO DO PORTUGUÊS PARA LIBRAS POR MEIO DA ELIS
}

\author{
TRANSLATING THE DIALECT OF THE CHARACTER CHICO BENTO \\ FROM PORTUGUESE TO LIBRAS THROUGH ELiS
}

\author{
TRADUCIENDO EL DIALECTO DEL PERSONAJE CHICO BENTO DEL \\ PORTUGUÊS PARA LIBRAS A TRAVÉS DE LA ELiS
}

Aline Alkimin Camargo Spicacci *

\section{Resumo}

Este artigo descreve o trabalho de tradução de duas tirinhas do personagem Chico Bento, de Maurício de Sousa, do português para a Libras, por meio da escrita ELiS, sistema criado por Barros. A partir de reflexões de teóricos da tradução e um diagnóstico de Senghas, Kita e Özyurek sobre a Língua de Sinais Nicaraguense emergente, que serviu de referência para as nossas soluções tradutórias, traçamos um paralelo entre o dialeto do personagem Chico Bento e o dialeto dos surdos da Nicarágua, pois tanto um como outros se encontram em situação de isolamento em relação à cultura dominante. Na Nicarágua os surdos produzem sinais mais icônicos, com uso recorrente de classificadores, que foram igualmente utilizados pelo personagem Chico Bento em nossas traduções.

Palavras-chave: Tradução. Libras. ELiS. Chico Bento.

\section{Introdução}

Neste artigo serão apresentadas duas traduções de tirinhas do personagem Chico Bento de Maurício de Sousa. A língua original das tirinhas é o português e a línguaalvo, a Libras. O público dessas traduções são crianças surdas em fase de alfabetização, aprendendo a escrita de sua língua pelo sistema ELiS (Escrita das Línguas de Sinais). A ELiS é uma ferramenta de escrita em sinais ainda recente, criada por Mariângela E.

\footnotetext{
* Graduação em Artes Visuais/Design Gráfico - UFG. Bacharelado em Letras: Tradução e Interpretação em Libras/Português - UFG. Mestranda em Estudos da Tradução pela Universidade Federal de Brasília (UnB). E-mail: alinealk@gmail.com
} 
Barros (2015) e colocada em prática em 2010 nos cursos de Libras da Universidade Federal de Goiás. Inspirada no sistema de notação de Willian Stokoe, que tinha base alfabética, linguística e linear, a Elis difere de outras formas de escrita criadas anteriormente, como a SignWriting, de Valérie Sutton, por ser alfabética e linear.

Esse sistema de escrita, a ELiS, é formado por 95 visografemas, formas gráficas que representam elementos visuais, divididos em quatro grupos: Configuração de Dedos (CD) com 10 visografemas; Orientação da Palma (OP) com 6 visografemas; Ponto de Articulação (PA) com 35 visografemas; e Movimento (M) com 44 visografemas. Para formar um sinal/palavra, grosso modo, devem-se juntar os quatro visografemas em sequência.

Para o desenvolvimento desta pesquisa, escolheu-se a tradução de tirinhas em decorrência da relação texto-imagem, presente nesse gênero textual. A Libras é uma língua visual e se o público-alvo são crianças em fase de alfabetização, vincular texto e imagem pode estimular o aprendizado. A escolha do personagem Chico Bento para esta pesquisa deve-se a sua fala peculiar. Chico Bento é um personagem rural que usa dialeto ${ }^{1}$ próprio, característico de regiões interioranas, e o fato de não utilizar uma fala de prestígio para se comunicar, permite um paralelo linguístico com a comunidade surda, que utiliza a Libras, uma língua de sinais.

Durante décadas, no Brasil, por diferentes motivos os surdos viveram afastados da sociedade. Muitos desenvolveram um dialeto de sinais caseiro, limitado às conversas com seus familiares. Isso acontecia devido a diferentes circunstâncias: por discriminação social, por vergonha de ser surdo ou ter um surdo na família, porque a família desconhecia a cultura surda, ou até por imposição médica.

O discurso médico tem muito mais força e prestígio do que o discurso da diversidade, do reconhecimento linguístico e cultural das minorias surdas. A surdez é construída na perspectiva do déficit, da falta, da anormalidade. O "normal" é ouvir, o que diverge desse padrão deve ser corrigido, "normalizado". Nesse processo normalizador, abrem-se espaços para a estigmatização e para a construção de preconceitos sociais (GESSER, 2009, p. 67).

Ainda hoje, muitas crianças surdas chegam à escola sem saber a Libras e precisam de professores que conheçam estratégias para auxiliá-las na fase inicial de contato com a sua língua natural. O objetivo deste trabalho é descrever o processo de tradução de tirinhas da personagem Chico Bento, com a observação do uso de uma 
linguagem que faça a ponte entre os sinais informais, utilizados em casa, e a formalidade, foi o meio que se imaginou para facilitar esse aprendizado. Traduzir sem perder o dialeto específico e a graça de uma língua foi o problema que gerou esta pesquisa.

\section{A tradução}

A tradução é sempre um desafio a cada texto. Não há uma tradução "perfeita" ou "correta", o resultado tradutório dependerá das línguas e culturas envolvidas, do objetivo, do tempo, do público, da mente criativa do tradutor e de outros vários fatores que podem influenciar no trabalho de tradução. Segundo Oustinoff, não há "tradução 'neutra' ou 'transparente' através da qual o texto original apareceria idealmente como em um espelho, identicamente" (2011, p. 22), ou seja, a tradução nunca será igual ao original, pois constituirá um novo texto, inserido em outro contexto.

De fato, a tradução é um novo texto construído em outra língua. Com base nos estudos de Lederer (1994), Munday (2012, p. 119) divide a tradução em três etapas: leitura e compreensão do texto original; desverbalização, que seria a decodificação do texto para entendê-lo em sua essência; e reverbalização, ou seja, a recodificação dos significados em outra língua e cultura.

Ao recodificar, o tradutor precisa reconstruir o texto, utilizando o máximo de elementos estilísticos presentes na obra original. Se for um poema, a métrica e a rima do texto fonte devem ser reproduzidas no texto da tradução. Contudo, no caso de um texto técnico, como bulas de medicamentos ou manuais de instrução, a prioridade é a exatidão das informações, ou seja, do conteúdo. Da forma ao conteúdo, o importante é buscar o máximo de fidelidade.

Esse tema, a fidelidade na tradução, sempre foi polêmico. Autores alemães dos séculos XVIII E XIX defendiam a fidelidade ao texto original, enquanto os da tradição francesa, que produziram, entre os séculos XVII e XVIII, obras conhecidas como Les Belles infidèles, postulavam a fluência e a liberdade nas traduções, defendendo a fidelidade ao público alvo. Essas duas perspectivas dificilmente entrarão em acordo. Neste trabalho, procurou-se manter a fidelidade ao original, transportando o chiste, a comicidade, e a variação linguística. Também se valorizou a fidelidade ao texto meta, quando procuramos meios de adaptar a variação linguística à comunidade receptora, mantendo a comicidade da tirinha. 
Sobre os aspectos cômicos de uma obra, Britto (2012, p. 48) afirma que "um texto que provoque o riso no original deve provocar o riso em seu leitor" na versão traduzida. Por outro lado, Rónai observa que para tal proeza, "é preciso, naturalmente, que um espírito zombeteiro se encontre num momento feliz de inspiração" (1981, p. 42). Para Rónai, o trocadilho, em uma tradução é geralmente "intraduzível por definição ou, noutras palavras, perde todo o chiste na tradução" (1981, p. 42). A comicidade, um dos elementos-chave deste trabalho, pode ser intraduzível, mas nada impede que seja recriada. Na verdade, não há tradução que seja "neutra" ou "transparente". O tradutor, em certos momentos, se torna autor, pois para transmitir ao público-alvo o humor do original é preciso recriar.

Bessa (2010) defende a necessidade de trocas de expressões de uma língua para outra, visando equivalências de significado. O texto é focado em tradução técnica, mas acreditamos que também pode ser aplicado em tradução literária, principalmente quando o tradutor se encontra diante de elementos julgados "intraduzíveis". Neste trabalho, deparamo-nos também com o desafio estilístico, pelo fato de o personagem se expressar usando um dialeto rural. Bessa menciona a questão do dialeto na tradução fazendo a seguinte consideração:

\footnotetext{
Questiona-se como achar um dialeto equivalente para o mineirismo ou o falar do sertanejo em alemão? Pode-se, quando muito, achar um dialeto que talvez seja culturalmente correspondente, dadas as principais características de seus falantes, e venha ainda eventualmente desempenhar um papel semelhante, mas nunca será algo aproximado o suficiente a ponto de passar a configuração correta desse tipo popular (2010, p. 55).
}

Diante das dificuldades de traduzir com fidelidade, especialmente quando se considera a especificidade cultural, procurou-se uma solução tradutória que permitisse a criação, em certas situações, e exigisse fidelidade, em outros momentos, na busca de uma proposta de tradução que valorizasse o equilíbrio e a adequação.

\section{Um estudo sobre a Língua de Sinais Nicaraguense}

A Nicarágua tem hoje, aproximadamente, seis milhões de habitantes e sua língua oficial é o espanhol. Segundo uma pesquisa de Senghas, Kita e Özyürek (2004), publicada na revista Science, antes de 1970, quando a população nicaragüense tinha em 
torno de dois milhões e meio de habitantes, os surdos, em sua maioria, viviam isolados e raramente se encontravam. Em decorrência disso, não havia uma língua de sinais constituída e era corrente o uso assistemático de sinais caseiros para a comunicação entre os surdos e suas famílias.

Com a abertura de escolas para educação especial na Nicarágua, em 1977, o cenário mudou e os surdos começaram a participar do convívio social. O ensino, realizado apenas em espanhol, de acordo com Senghas, Kita e Özyürek (2004), não era eficiente para as crianças surdas, que logo começaram a desenvolver, espontaneamente, um sistema de gestos, o qual se expandiu, tomando a forma de uma primitiva língua de sinais. Neste novo cenário, surgiu a LSN, Língua de Sinais Nicaraguense ou ISN, Idioma de Señas de Nicaragua.

A pesquisa acompanhou 40 pessoas, sendo 30 surdos e 10 ouvintes. Os surdos foram divididos em 3 grupos, de acordo com o ano em que cada um deles fora expostos à ISN pela primeira vez. O grupo 1 era formado por 10 surdos que tiveram contato com a ISN antes de 1984. O grupo 2, por 10 surdos que tiveram contato com a ISN entre 1984 a 1993. O grupo 3, também formado por 10 surdos, teve contato com a ISN depois de 1993. Os 30 surdos aprenderam a ISN com seis anos, ou até menos idade e foram comparados com um grupo de 10 ouvintes de fala espanhola.

O objetivo era comparar a produção gestual dos dois grupos, realizada concomitante à fala. Na pesquisa, foi exibida uma animação em vídeo e solicitado aos participantes que recontassem a história. Os ouvintes contaram em espanhol, mas somente os gestos que realizaram durante a narrativa foram levados em consideração na pesquisa. O objetivo era comparar o tipo de produção em cada grupo. A animação mostrava um gato rolando em uma ladeira, um evento em que o movimento do personagem envolvia trajetória e modo (direção descendente e rolamento respectivamente).

Nas línguas, em geral, modo e trajetória são codificados separadamente e recombinados de acordo com a situação. No português, a palavra "rolando" é o modo e a expressão "para baixo", a trajetória. Ao juntar os dois elementos temos "rolando para baixo". Em línguas de sinais, representar esse evento com os dois aspectos, modo e trajetória, simultaneamente, é mais icônico.

Foi observado que $100 \%$ dos ouvintes e a maioria dos surdos do grupo 1 produziram o evento de movimento de forma icônica, ou seja, com os dois elementos 
realizados simultaneamente. A maioria dos surdos dos grupos 2 e 3 produziram o evento de forma sequencial, ou seja, apresentando os dois aspectos articulados separadamente. Isso mostra que os surdos do grupo 1 aprenderam uma língua menos sistematizada, em uma época que a ISN não estava estruturada gramaticalmente, enquanto os surdos dos grupos 2 e 3 apresentaram uma evolução sistêmica na estrutura gramatical de sua sinalização, considerando que apresentaram sinais tanto para a categoria trajetória como para a categoria modo. Com essa pesquisa, Senghas, Kita e Özyürek (2004) buscaram demonstrar que a língua de sinais é capaz de se expressar além da iconicidade, estando apta a se tornar uma língua com características complexas.

\section{Os classificadores e os gestos}

Como visto na seção anterior, o grupo 1, composto por surdos que tiveram contato com a ISN pela primeira vez antes de 1984, produziu o evento de movimento com os dois aspectos (modo e trajetória) simultaneamente. Mostrando que executam a língua de forma ainda assistemática, já que a aprenderam na fase de seu surgimento. Os falantes de língua oral também produziram gestos que podem ser considerados classificadores. Sobre os classificadores nas línguas orais, Emmorey (2003) afirma que têm significado e ocorrem como morfemas, sob condições específicas, em estruturas de superfície.

Nas línguas de sinais, os termos "classificadores" e "gestos" têm significados discutíveis. A distinção entre esses dois termos não é clara e eles parecem se confundir constantemente. Gestos não são gramaticalizados e podem ser considerados um universal linguístico, pois falantes da língua oral e sinalizada utilizam este recurso como componente de sua expressão. Segundo Carneiro, os gestos "não podem ser vistos a partir de uma ação física, mas de uma noção semiótica, já que expressam o lado imagético do pensamento durante o discurso" (2016, p. 122). Carneiro observa que os classificadores, numa visão tradicional, constituem:

[...]sinais polimorfêmicos, estruturas icônicas em que cada aspecto formacional é um morfema classificador, dentre eles: a configuração de mão, o movimento realizado pela mão, característica do movimento, ponto inicial e final do movimento, orientação da palma, disposição do corpo do sinalizante e a disposição de parte do corpo do sinalizante. Cada parâmetro, dispondo de traços, caracterizaria um grupo de referentes (2016, p.122). 
A iconicidade está presente tanto nos classificadores quanto nos gestos, o que traz a confusão entre tais categorias. Essa proximidade abre um leque de questionamentos que ainda devem ser discutidos e pesquisados. Os sinais das línguas sinalizadas, não pertencem às categorias dos gestos e classificadores, mas também podem ser icônicos ou provenientes da iconicidade e embora alguns se tornem arbitrários, outros continuam icônicos. Para Carneiro, essa similaridade "entre não sinalizantes e sinalizantes na representação de movimento e relação espacial corrobora a ideia de que as línguas sinalizadas partilham algumas propriedades gestuais" (2016, p.126). Sobre as diferença entre os classificadores das línguas sinalizadas e os gestos, podemos considerar que o sinal para ANDAR necessita da incorporação de um agente para executá-lo. Assim, se for a representação de uma pessoa andando poderá ser feito somente com o dedo indicador levantado, se for um elefante andando, as mãos serão fechadas e executadas com peso, no caso da representação do andar de um cachorro, o punho se move levemente. Na figura 1, Felipe (2007) faz um levantamento dos morfemas de maior ocorrência na execução de classificadores em Libras:

Figura 1 - Morfemas mais recorrentes em Libras.

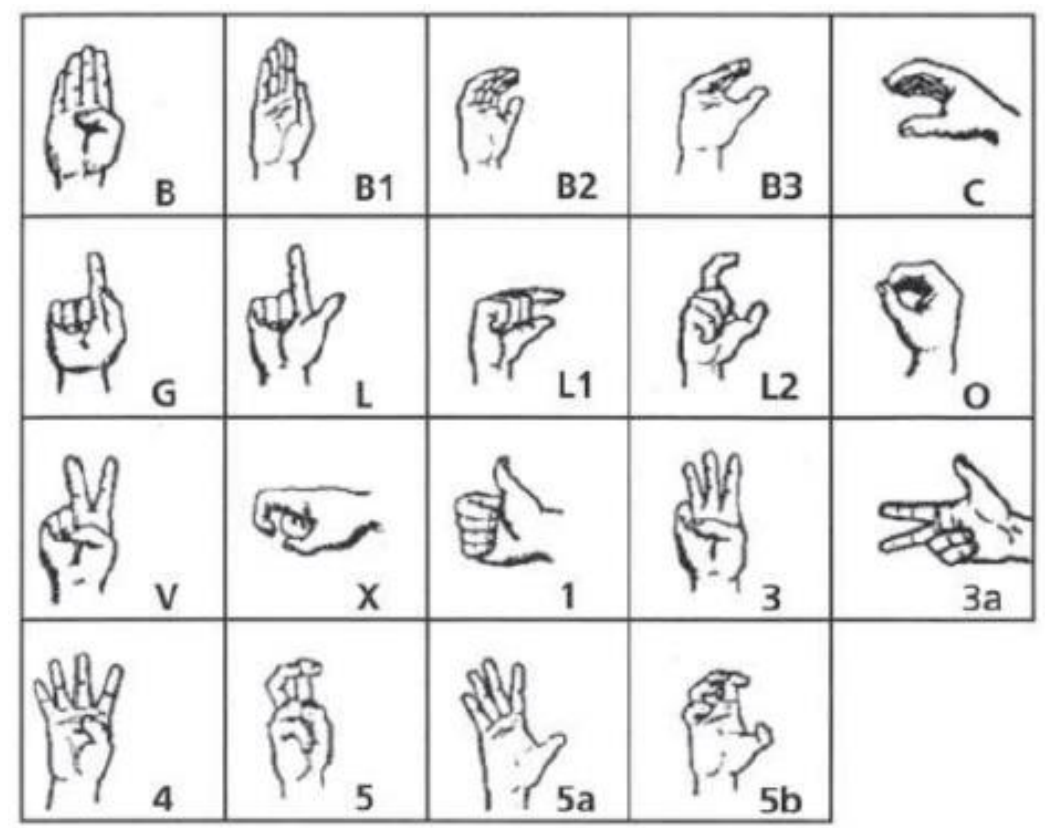

Fonte: Felipe (2007, p. 173).

Essa sequência de imagens apresenta as configurações de mão que ocorrem com mais frequência na formação de um classificador. Embora não sejam as únicas, são as 
mais utilizadas. A partir dessas considerações iniciais, fizemos a tradução das breves frases que compõem as tirinhas da personagem Chico Bento, buscando um registro mais próximo do informal, por meio do uso de classificadores da Libras e dos gestos icônicos que são reconhecidos de forma universal por surdos e ouvintes.

\section{Traduzindo o dialeto rural do Chico Bento}

A partir dos estudos sobre o desenvolvimento da Língua de Sinais da Nicarágua (ISN), foi concebido um paralelo cultural entre o dialeto do Chico Bento, menino interiorano que vive no meio rural, e o dialeto do surdo nicaragüense, que vivia isolado antes de 1970. Os sinais caseiros produzidos por estes surdos poderiam ser comparados ao dialeto rural, na medida em que ambos se distanciam de uma norma padrão.

Ressalta-se que, nesse paralelo, não foi levada em consideração a oposição entre o meio físico rural e urbano, mas a questão cultural de afastamento de uma língua normatizada. No caso, o personagem Chico Bento é afastado da língua normatizada por um deslocamento cultural e geográfico, enquanto os surdos, que não conhecem uma língua de sinais normatizada,são afastados por uma questão cultural.

Vimos que os classificadores não são gestos, mas às vezes são confundidos com eles pela iconicidade que carregam. Foi nesse sentido que elegemos tanto os classificadores como os gestos para representar a ponte entre a linguagem da criança surda que chega à escola com os sinais caseiros e uma língua sistematizada e utilizada na escola, a Libras. Nas tirinhas do Chico Bento, a fala do personagem apresenta marcas de linguagem que caracterizam o falar típico de pessoas do meio rural. A tradução, de certa forma, deve manter este equilíbrio cultural, carregando, na mesma medida, marcas de linguagem.

A teoria de tradução apresentada por Cristiane Nord (1991) é funcionalista, apresentando um Modelo Circular, que pretende avaliar fatores como a cultura de chegada, a cultura de saída, assim como o texto fonte. Para Nord, o mais importante em uma tradução é a situação comunicativa. Para facilitar o processo tradutório das tirinhas do Chico Bento, utilizamos a tabela de Nord (1991), exposta abaixo, na Tabela 1, que relaciona tanto os fatores internos do texto quanto os fatores externos ao texto, possibilitando ao tradutor uma rápida visualização dos fatores envolvidos e expondolhe, de forma sistemática, o caminho tradutório que ele deve trilhar. 
Tabela 1- Modelo de Cristiane Nord.

\begin{tabular}{|l|l|}
\hline Fatores Internos & Fatores Externos \\
\hline Emissor & Tema \\
\hline Intenção & Conteúdo \\
\hline Receptor & Pressuposições \\
\hline Meio & Estruturação \\
\hline Lugar & Elementos não verbais \\
\hline Tempo & Léxico \\
\hline Propósito (motivo) & $\begin{array}{l}\text { Elementos } \\
\text { suprassegmentais }\end{array}$ \\
\hline Função textual & Efeitos do texto \\
\hline
\end{tabular}

A partir do modelo proposto por Nord (1991), considerando os fatores internos e externos, iniciamos o processo de tradução do texto fonte para o texto meta.

Tabela2 - Aplicação do Modelo de Nord para a primeira tira.

\begin{tabular}{|c|c|c|c|}
\hline \multicolumn{4}{|c|}{ Fatores externos } \\
\hline & Texto Fonte & $\begin{array}{l}\text { Questões de } \\
\text { Tradução }\end{array}$ & Texto-meta \\
\hline Emissor & Maurício de Sousa & $\begin{array}{l}\text { Contribuições da } \\
\text { orientadora. }\end{array}$ & Autora do artigo. \\
\hline Intenção & Entretenimento & & $\begin{array}{l}\text { Entretenimento e material } \\
\text { de apoio na alfabetização } \\
\text { do surdo. }\end{array}$ \\
\hline Receptor & $\begin{array}{l}\text { Crianças e adultos que leem } \\
\text { português. }\end{array}$ & & $\begin{array}{l}\text { Crianças surdas em fase de } \\
\text { alfabetização em Libras e } \\
\text { adultos aprendendo ELiS }\end{array}$ \\
\hline Meio & Site da Turma da Mônica. & $\begin{array}{l}\text { Primeiramente } \\
\text { apresentadas em } \\
\text { artigo de TCC. }\end{array}$ & $\begin{array}{l}\text { Futuramente o material } \\
\text { poderá ser disponibilizado } \\
\text { de forma online. }\end{array}$ \\
\hline Lugar & Brasil & & Brasil \\
\hline Tempo & $\begin{array}{l}\text { Chico Bento, criado em } \\
\text { 1961, é produzido até hoje. }\end{array}$ & & Início do projeto em 2017. \\
\hline
\end{tabular}




\begin{tabular}{|c|c|c|c|}
\hline Propósito (motivo) & $\begin{array}{l}\text { Maurício de Sousa criou o } \\
\text { personagem baseado em seu } \\
\text { tio-avô morador de Santa } \\
\text { Branca/SP. }\end{array}$ & & $\begin{array}{l}\text { Permitir leitura e acesso } \\
\text { aos textos em português } \\
\text { para a Libras. }\end{array}$ \\
\hline Função Textual & Função humorística & & Função humorística \\
\hline \multicolumn{4}{|c|}{ Fatores internos } \\
\hline Tema & Chico Bento & & Chico Bento \\
\hline Conteúdo & Trabalho na roça. & & Trabalho na roça. \\
\hline Pressuposições & $\begin{array}{l}\text { Que o público saiba } \\
\text { ler em português e } \\
\text { compreenda que o } \\
\text { trabalho é penoso. }\end{array}$ & & $\begin{array}{l}\text { Que o público saiba ler } \\
\text { em ELiS, ou esteja } \\
\text { aprendendo. E } \\
\text { compreenda que o } \\
\text { trabalho é penoso. }\end{array}$ \\
\hline Estruturação & $\begin{array}{l}1 \text { balão de fala no } \\
\text { último quadro. }\end{array}$ & & $\begin{array}{l}1 \text { balão de fala no último } \\
\text { quadro. }\end{array}$ \\
\hline Elementos não verbais & $\begin{array}{l}1 \text { tirinha com } \\
\text { 3quadros. }\end{array}$ & & 1 tirinha com 3 quadros. \\
\hline Léxico & $\begin{array}{l}\text { Português informal, } \\
\text { dialeto rural. }\end{array}$ & $\begin{array}{l}\text { Utilizamos o gesto, } \\
\text { mas os classificadores } \\
\text { também poderiam ser } \\
\text { usados. }\end{array}$ & $\begin{array}{l}\text { Libras informal, } \\
\text { utilização de gesto. }\end{array}$ \\
\hline Sintaxe & $\begin{array}{l}\text { Estrutura da língua } \\
\text { portuguesa. }\end{array}$ & $\begin{array}{l}\text { Do alfabeto romano } \\
\text { para ELiS. }\end{array}$ & $\begin{array}{l}\text { Estrutura da Libras } \\
\text { utilizando ELiS. }\end{array}$ \\
\hline $\begin{array}{l}\text { Elementos } \\
\text { suprassegmentais }\end{array}$ & $\begin{array}{l}\text { Escrito da forma que } \\
\text { se fala. }\end{array}$ & & Descrição do gesto. \\
\hline Efeitos do texto & Causar humor. & $\begin{array}{l}\text { Manter a comicidade e } \\
\text { a informalidade. }\end{array}$ & Causar humor. \\
\hline
\end{tabular}

A primeira tirinha do Chico Bento tem apenas um balão com o texto: "Crescê num é nada fácir!", que em uma tradução direta para Libras poderia ser "CRESCER FÁCIL NÃO!". No entanto, essa opção, apesar de transmitir o conteúdo semântico, desconsidera o aspecto pragmático dialetal.

Outra possibilidade seria a de traduzir a frase para Libras por "CRESCER DIFÍCIL!", utilizando o recurso de modulação ${ }^{2}$, em que se altera o ponto de vista de uma negação "nada fácir", para uma afirmação "DIFÍCIL". O uso desse recurso também nos levaria a incorrer na mesma falha, ou seja, desrespeitar o registro linguístico do texto fonte. 
Figura 2: Tradução da primeira tirinha para ELiS.

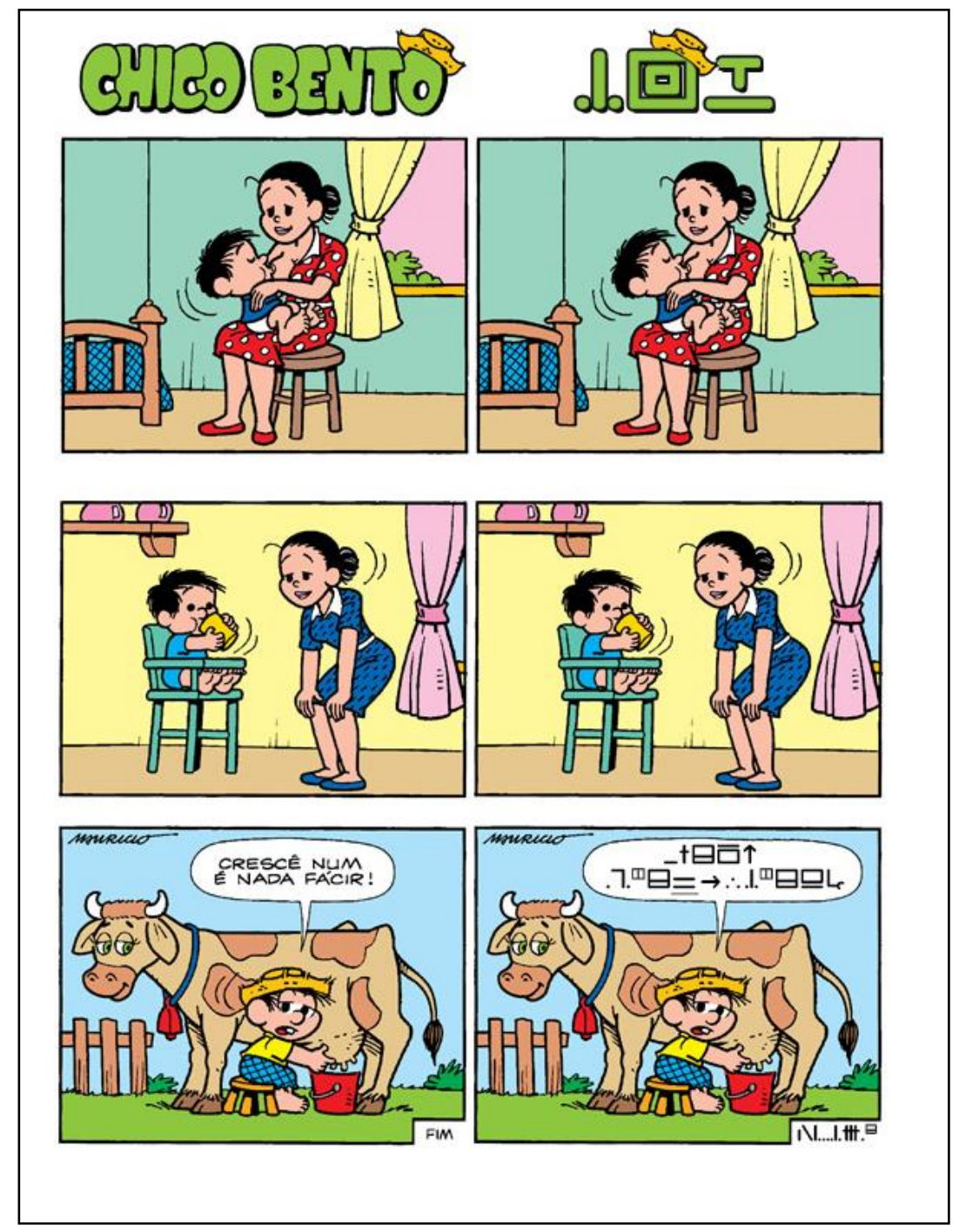

Fonte: Site da Turma da Mônica (UOL), Tirinha 26.

A solução encontrada foi traduzir a expressão "nada fácir" por "SUOR-NATESTA", que representa a dificuldade de um trabalho que foi realizado com muito suor e não é um sinal gramaticalizado na Libras. 
Tabela3 - Aplicação do Modelo de Nord para a segunda tira.

\begin{tabular}{|c|c|c|c|}
\hline \multicolumn{4}{|c|}{ Fatores Externos } \\
\hline & Texto Fonte & Questões de Tradução & Texto-meta \\
\hline Emissor & Maurício de Sousa & $\begin{array}{l}\text { Contribuições da } \\
\text { orientadora de TCC. }\end{array}$ & Autora da tradução \\
\hline Intenção & Entretenimento & & $\begin{array}{c}\text { Entretenimento e } \\
\text { material de apoio na } \\
\text { alfabetização do surdo. }\end{array}$ \\
\hline Receptor & $\begin{array}{l}\text { Crianças e adultos que } \\
\text { leem português. }\end{array}$ & & $\begin{array}{l}\text { Crianças surdas em fase } \\
\text { de alfabetização em } \\
\text { Libras e adultos que } \\
\text { estão aprendendo ELiS }\end{array}$ \\
\hline Meio & Blog na internet. & $\begin{array}{c}\text { Primeiramente } \\
\text { apresentadas em artigo } \\
\text { de TCC. }\end{array}$ & $\begin{array}{c}\text { Futuramente o material } \\
\text { poderá ser } \\
\text { disponibilizado de } \\
\text { forma online. }\end{array}$ \\
\hline Lugar & Brasil & & Brasil \\
\hline Tempo & $\begin{array}{c}\text { Personagem Chico } \\
\text { Bento criado em } 1961 \text { e } \\
\text { é produzido até hoje. }\end{array}$ & & $\begin{array}{l}\text { Início do projeto no ano } \\
\text { de } 2017 .\end{array}$ \\
\hline Propósito (motivo) & $\begin{array}{l}\text { Maurício de Sousa } \\
\text { criou o personagem } \\
\text { para representar o seu } \\
\text { tio-avô morador de } \\
\text { Santa Branca/SP. }\end{array}$ & & $\begin{array}{c}\text { Permitir a leitura e } \\
\text { acesso aos textos em } \\
\text { português para a Libras, } \\
\text { língua própria dos } \\
\text { surdos que moram no } \\
\text { Brasil. }\end{array}$ \\
\hline Função Textual & Função humorística & & Função humorística \\
\hline \multicolumn{4}{|c|}{ Fatores Internos } \\
\hline Tema & Chico Bento & & Chico Bento \\
\hline Conteúdo & $\begin{array}{c}\text { Chico Bento se } \\
\text { confessando com o } \\
\text { padre. }\end{array}$ & & $\begin{array}{l}\text { Chico Bento se } \\
\text { confessando com o } \\
\text { padre. }\end{array}$ \\
\hline Pressuposições & $\begin{array}{l}\text { Que o público saiba ler } \\
\text { em português. E } \\
\text { interprete que o Chico é } \\
\text { preguiço. }\end{array}$ & & $\begin{array}{l}\text { Que o público saiba ler } \\
\text { em ELiS, ou esteja } \\
\text { aprendendo. E } \\
\text { interprete que o Chico é } \\
\text { preguiço. }\end{array}$ \\
\hline Estruturação & $\begin{array}{l}1 \text { tirinha com } 2 \text { quadros } \\
\text { e } 4 \text { balões de fala. Três } \\
\text { no primeiro quadro e } 1 \\
\text { no segundo quadro. } \\
\text { Forma de diálogo. }\end{array}$ & & $\begin{array}{l}1 \text { tirinha com } 2 \text { quadros } \\
\text { e } 4 \text { balões de fala. Três } \\
\text { no primeiro quadro e } 1 \\
\text { no segundo quadro. } \\
\text { Forma de diálogo. }\end{array}$ \\
\hline Elementos não verbais & $\begin{array}{c}1 \text { tirinha com } 2 \text { quadros } \\
\text { utilizando recursos } \\
\text { imagéticos. }\end{array}$ & & $\begin{array}{c}1 \text { tirinha com } 2 \text { quadros } \\
\text { utilizando recursos } \\
\text { imagéticos. }\end{array}$ \\
\hline Léxico & $\begin{array}{l}\text { Chico Bento falando } \\
\text { português informal por }\end{array}$ & $\begin{array}{l}\text { Poderão ser utilizados } \\
\text { classificadores ou }\end{array}$ & $\begin{array}{l}\text { Chico Bento usando a } \\
\text { Libras informal. Padre }\end{array}$ \\
\hline
\end{tabular}




\begin{tabular}{|c|c|c|c|}
\hline & $\begin{array}{l}\text { meio do dialeto rural. E } \\
\text { o padre falando de } \\
\text { maneira formal e não } \\
\text { marcada. }\end{array}$ & gestos. & $\begin{array}{l}\text { utilizando a Libras } \\
\text { formal. }\end{array}$ \\
\hline Sintaxe & $\begin{array}{c}\text { Estrutura da língua } \\
\text { portuguesa. }\end{array}$ & $\begin{array}{c}\text { Do alfabeto romano } \\
\text { para o alfabeto em } \\
\text { ELiS. }\end{array}$ & $\begin{array}{c}\text { Estrutura da Libras } \\
\text { utilizando ELiS. }\end{array}$ \\
\hline $\begin{array}{c}\text { Elementos } \\
\text { suprassegmentais }\end{array}$ & $\begin{array}{l}\text { Escrito da forma que se } \\
\text { fala. }\end{array}$ & & \\
\hline Efeitos do texto & Causar humor. & $\begin{array}{l}\text { Manter a comicidade e } \\
\text { a informalidade do } \\
\text { Chico Bento. }\end{array}$ & Causar humor. \\
\hline
\end{tabular}

$\mathrm{Na}$ segunda tirinha são apresentados dois personagens. Um deles é o Chico Bento e o outro, um padre que não utiliza o dialeto rural. Dessa forma, foi necessáario observar o contraste cultural e reproduzi-lo na conversa entre os dois, com o personagem Chico usando classificadores e gestos, marcas de uma fala informal, e o padre mantendo um padrão formal de sinalização.

Figura 3: Tradução da segunda tirinha para ELiS

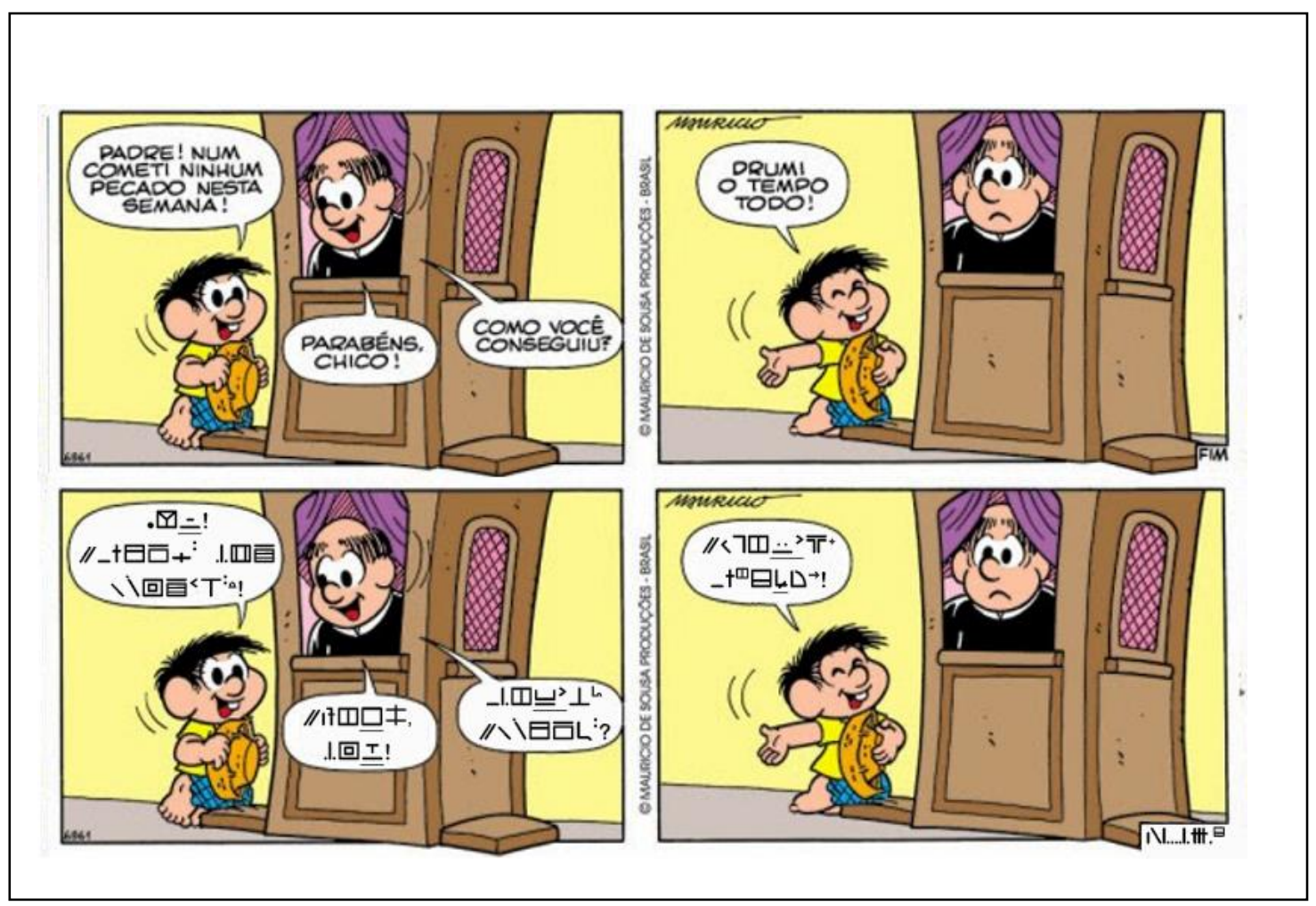

Fonte: Blog Admirável Juju, 
O padre tem dois balões de fala: "Parabéns, Chico!" e "Como você conseguiu?", que foram traduzidos em Libras com os sinais "PARABÉNS, sinalCHICO ${ }^{3}$ !" e “CONSEGUIR COMO?”. Ambas as traduções condizem com a Libras formal. O personagem Chico Bento também tem dois balões de fala: "Padre! Num cometi ninhum pecado nesta semana!" e "Drumi o tempo todo!". O primeiro balão começa com um vocativo: "padre". Como o uso de vocativo em Libras é muito reduzido, optamos por recorrer ao procedimento tradutório de transposição ${ }^{4}$, que é utilizado quando é necessário traduzir uma categoria gramatical inexistente na outra língua, e decidimos traduzir "padre" por "BÊNÇÃO".

A sequência do balão "Num cometi ninhum pecado nesta semana!" ficou assim: “HOJE EU PECADO-NÃO". O sinal "HOJE" em vez de "SEMANA", foi escolhido para combinar com o último quadrinho da tirinha que ficou assim: "DORMIR DIATODO!”. Ficaria muito extenso explicar que o personagem dormiu o dia todo em todos os dias da semana, enquanto que, passar a ideia de apenas um dia não traz grandes mudanças ao teor da história. Se colocássemos "DORMIR SEMANA TODA", poderia parecer que o Chico tinha dormido a semana toda sem acordar e não passaria a ideia de folga e fuga do trabalho. Utilizar os sinais “DORMIR TEMPO TODO” não condiz com a gramática da Libras, é uma frase agramatical, ou ainda, como em geral é definido esse fenômeno, uma frase em "português sinalizado", em que se faz uma tradução direta dos os sinais, palavra por palavra, sem considerar a sintaxe da Libras. Para expressar a ideia de "dormir muito tempo" em Libras, a noção de "tempo" precisa ser quantificada (DIA, MÊS, HORAS...), e escolhemos o sinal "DIA” para expressá-la em nossa tradução.

\section{Conclusão}

Neste trabalho, deparamo-nos com vários desafios tradutórios. A busca por melhores resultados para os problemas de tradução encontrados nas tirinhas da personagem Chico Bento, nos levou a diferentes teóricos e também a pesquisas históricas e culturais. Para traduzir, não basta criatividade. É necessário imergir em ambas as culturas, tanto na cultura da língua de partida, como na da língua de chegada. Fazer essa ponte com qualidade requer aprofundamento nos estudos das línguas e aporte teórico. Sobre as dificuldades que marcam o processo tradutório e a qualidade dos resultados do trabalho final, Paulo Henriques Britto (2012, p. 44 e 45) afirma a 
necessidade de se "aprender a conviver com o imperfeito e incompleto. [...] O fato de que não podemos jamais atingir a perfeição não deve nos desanimar nem nos levar a mudar de meta".

Neste trabalho, a maior dificuldade encontrada foi o dialeto de Chico Bento, um personagem que vive no meio rural, o que poderia, para muitos profissionais, parecer algo intraduzível. Considerando que o dialeto é marca específica de uma língua e cultura, concordamos que não há um equivalente perfeito em Libras, e nem sequer uma correspondência aproximada. No entanto, foi possível encontrar uma solução tradutória, mostrando ser possível transmitir, em língua de sinais, mensagem semelhante, em relação ao original ${ }^{5}$.

\begin{abstract}
This article describes the translation process of two strips of the character Chico Bento, by Maurício de Sousa, from Portuguese to Libras, through ELiS, a writing system created by Barros. From some reflections of translation theorists and a diagnosis of Senghas, Kita and Özyurek on the emerging Nicaraguan Sign Language, which served as a reference for our translation solutions, we draw a parallel between the dialect of the character Chico Bento and the dialect of the deaf people from Nicaragua, since both are isolated from the dominant culture. In Nicaragua deaf people produce more iconic signs, with recurring use of classifiers, which were also used by the character Chico Bento in our translations.
\end{abstract}

Keywords: Translation. Libras. ELiS. Chico Bento.

\title{
Resúmen
}

En este artículo se describe el trabajo de traducción de dos tiras del personaje Chico Bento, de Mauricio de Sousa, del portugués para LIBRAS, a través de Elis, un sistema de escritura creado por Barros. A partir de algunas reflexiones de teóricos de la traducción y un diagnóstico de Senghas, Kita y Özyurek sobre la Lengua de Señales Nicaragüense emergente, que sirvió de referencia para nuestras soluciones en la traducción, trazamos un paralelo entre el dialecto del personaje Chico Bento y el dialecto de los sordos de Nicaragua, pues tanto uno como los otros se encuentram en situación de aislamiento en relación a la cultura dominante. En Nicaragua los sordos producen señales más icónicas, con el uso recurrente de clasificadores, los quales serán igualmente utilizados por el personaje Chico Bento en nuestras traducciones.

Palabras clave: Traducción. Libras. ELiS. Chico Bento. 


\section{Referências}

BARBOSA, Heloisa Gonçalves. Procedimentos técnicos da tradução: Uma nova proposta. Campinas: Pontes, 1990.

BARROS, Mariângela Estelita. ELiS: Sistema brasileiro de escrita das línguas de sinais. Porto Alegre: Penso, 2015.

BESSA, Cristiane Roscoe. A tradução-substituição. Brasília: Editora do Centro, 2010.

BRITTO, Paulo Henriques. A tradução literária. Rio de Janeiro: Civilização Brasileira, 2012.

CARNEIRO, Bruno. "Corpo e classificadores nas línguas de sinais". Revista Sinalizar, v.1, n.2, p. 118-129, jul./dez. 2016.

EMMOREY, K.. (Ed) Perspectives on classifer constructions in signed languages. Mahwah, N.J. : Lawrebce Erlbaum Associates, 2003. p. 221-246. Disponível em: https://academic.oup.com/jdsde/article/9/3/345/508608 Acesso em 10 abr. 2018.

FELIPE, Tanya A. Libras em contexto: Curso básico. Rio de Janeiro: WalPrint Gráfica e Editora, 2007.

GESSER, Audrei. LIBRAS? Que língua é essa? : Crenças e preconceitos em torno da língua de sinais e da realidade surda. São Paulo: Parábola, 2009.

LEDERER, M.. La Traduction Aujourd'hui: Le Modèle Interprétatif. Paris: Hachette, 1994.

MUNDAY, Jeremy. Introducing translation studies: theories and applications. Londres: Routledge, 2012.

NORD, Christiane. Text analysis in translation : Theory, Methodology, and Didactic Application of a Model for Translation-Oriented Text Analysis. Amsterdam/New York: Rodopi, 1991.

OUSTINOFF, Michaël. Tradução: histórias, teorias e métodos. Trad. Marcos Marcionilo. São Paulo: Parábola, 2011.

RÓNAI, Paulo. A tradução vivida. Coleção Logos. Rio de Janeiro: Nova Fronteira, 1981.

SENGHAS, A., S. KITA, and A. ÖZYÜREK (2004). "Children creating core properties of language: evidence from an emerging sign language in Nicaragua". Science, 305: 5691, 1779-1782. 17 de set. 2004.

SOUZA, Mauricio. Site da Turma da Mônica, Tirinha 26. UOL. Disponível em: http://turmadamonica.uol.com.br/quadrinhos/?tg_personagem=chico-bento\&tg quadrinho =tirinhas. Acesso: 20 jun. 2017. 
Blog Admirável Juju, Chico Bento e o padre. Disponível em:

http://www.admiraveljuju.com.br/post/18/chico_bento_e_o_padre/.Acesso: 10set. 2017.

\section{Notas}

${ }^{1}$ Dialeto é o conjunto de marcas linguísticas de natureza semântico-lexical, morfossintática e fonéticomorfológica, restrito a uma comunidade inserida numa comunidade maior de usuários da mesma língua.

${ }^{2}$ Modulação é um dos procedimentos descritos por Heloísa Barbosa (1990).

${ }^{3} \mathrm{O}$ sinal Chico é aquele que o personagem recebeu da comunidade surda. Semelhante a um nome de batismo em língua de sinais. É comum na cultura surda, um indivíduo surdo nomear o outro com um sinal que o caracterize.

${ }^{4}$ Transposição é um dos procedimentos descritos por Barbosa (1990).

${ }^{5}$ Artigo apresentado no evento "I Seminário de Trabalho de Conclusão de Curso - Letras: Tradução e Interpretação em Libras/Português" no dia 30 de novembro de 2017. 